\title{
Quality of Care Received by Children from 1 to 23 Months: Realities in the City of Antananarivo
}

\author{
Fidiniaina Mamy Randriatsarafara ${ }^{1}$, Domoina Zafindrasoa Rakotovao-Ravahatra ${ }^{2}$, Lantonirina \\ Ravaoarisoa $^{3}$, Ando Faramalalatiana Rafanomezantsoa ${ }^{4}$, Jean De Dieu Marie Rakotomanga ${ }^{5}$, \\ Vahiniarison Dieudonné Randrianarimanana ${ }^{6}$ \\ 1,3,4,Public Health Department of the Faculty of Medicine Antananarivo, Madagascar \\ ${ }^{2}$ Laboratory of Joseph Raseta Befelatanana University Hospital Antananarivo, Madagascar \\ ${ }^{5,6}$ National Institute of Public and Community Health, Antananarivo, Madagascar
}

\begin{tabular}{|c|c|}
\hline Article Info & ABSTRACT \\
\hline Article history: & Children's health depends on the proper care they receive from their mothers. \\
\hline Received Jun 30, 2018 & This study aims to describe the quality of care received by children from 1 to \\
\hline Revised Sep 5, 2018 & analytical study for a period from December 2016 to April 2017 in the city of \\
\hline Accepted Sep 12, 2018 & $\begin{array}{l}\text { Antananarivo which is the capital of Madagascar. The study population was } \\
\text { made up of } 420 \text { mother-child dyads living in the city of Antananarivo. }\end{array}$ \\
\hline Keyword: & $\begin{array}{l}\text { Regarding the care received by children, } 47.6 \%, 95 \% \text { Confidence Interval } \\
\text { (CI) }[42.8-52.4] \text { benefit from quality nutrition care, } 92.3 \%, 95 \% \text { CI [89.8- }\end{array}$ \\
\hline Care & 94.8], have a social care and $45.5 \%, 95 \%$ CI [40.9-50.5] receive health care. \\
\hline Hyoiene & The hygiene of life $66.4 \%, 95 \%$ CI [61.6-70.6] and the body hygiene $35.3 \%$, \\
\hline Hygiene & 95\% CI [30.6-39.8] improve as the child grows up. The care received by \\
\hline Infant health & children was complete for the five types in $7.6 \%, 95 \%$ CI [5.1-10.1]. With \\
\hline Mother & regard to the profile of the mother, mothers under the age of $18(\mathrm{OR}=3.25$, \\
\hline Nutrition & $\begin{array}{l}95 \% \text { CI }[1.07-9.46]) \text { and those who are single (OR=3.47, 95\% CI }[1.24- \\
9.35]) \text { offer more acceptable care to their infants. Infant care depends on the } \\
\text { socio-economic and demographic profile of the mother. Thus, it is important } \\
\text { to strengthen the communication strategy on infant first aid gestures and } \\
\text { mothers' education on childcare. }\end{array}$ \\
\hline
\end{tabular}

Copyright $@ 2018$ Institute of Advanced Engineering and Science. All rights reserved.

\section{Corresponding Author:}

Randriatsarafara Fidiniaina Mamy,

Public Health Department of the Faculty of Medicine Antananarivo,

Lot $050 \mathrm{~F}$ Bis Ambohibao Antehiroka. Antananarivo 105. Madagascar.

Email: fidyrfm@yahoo.fr

\section{INTRODUCTION}

Health is defined by the World Health Organization (WHO) as "a state of physical, mental, social well-being and not just an absence of disease or infirmity" [1]. To get closer to this well-being, every individual has the right to primary health care (PHC), including the infant [2].This care includes vaccination, access to drinking water, food, protection, hygiene and access to basic healthcare [3]. In fact, an improvement in the care of children made it possible to reduce the global under-five mortality rate from 75 to 48 deaths per thousand live births between 1990 and 2012 [4].In sub-Saharan Africa, the neonatal mortality rate remains high and children born in these countries are 12 times more likely to die before their fifth birthday [5]. In Madagascar, 47\% of children under 5 suffer from chronic malnutrition [6]. Breastfeeding is suboptimal in 14\% of children aged 0 to 6 months and 58\% of children aged 6 to 24 months [7]. And 42\% of children under 5 years old are deficient in Vitamin A [8]. The objectives of this study are to determine the prevalence of the different types of care received by children under 24 months of age and to identify the relationship between the socio-economic and demographic profile of mothers and the care received by these children. 


\section{RESEARCH METHOD}

This was a cross-sectional and analytical study for a period from December 2016 to February 2017 in the city of Antananarivo which is the capital of Madagascar. The study population was made up of motherchild dyads living in the city of Antananarivo. Inclusion criteria are mothers of children from 1 to 23 months of age and who are cared for by their mothers. The exclusion criteria are the eldest of the 2 children under 23 months and one of the twins under 23 months. The survey was carried out among the 195 Fokontany (the smallest administrative unit in the country), from the 6 districts of the municipality. The selection of the subjects was by cluster sampling method.

The sample size was 420 mother-child dyads. The number of people surveyed was 7 per cluster. When carrying out the survey the starting point is the center of the fokontany and the orientation was done by the technique of the bottle. This technique consists in putting the bottle in the center of the Fokontany, then turning it, and one goes towards the direction indicated by the head of the bottle. Quality of care was assessed using five categories of care received by the infant [9], namely: (i) body hygiene care which contains : daily bath, regular baths (every 2 to 3 days), change clothes at least once a day and ironing after each wash, change panties with each wet or saddle, change diapers at least 3 times a day or at each saddle, weekly nail clippers ; (ii) life hygiene, which contains age-appropriate sleep, mosquito net use, age-appropriate toys, play partner, walk, hat possession, sock, blanket; (iii) nutrition care which contains exclusive breastfeeding until 6 months of age, dietary diversification at 6 months of age, adequate nutrition, adequate food hygiene ; (iv) health care which contains correct vaccination (according to the EPI calendar), deworming (at least one dose of deworming received in over 12 months), vitamin A (one dose of vitamin every 6 months for more than 6 months), visit systematic (regular visit according to the age), medical consultation (every time the infant falls sick) ; and (v) social care which contains a copy of birth certificate and recognition of the biological father.

For each category, specific criteria were assessed. If more than two-thirds of the criteria are fulfilled, care is qualified as "quality care".

A pre-tested survey questionnaire administered to mothers was used for data collection. Subsequently, the collected data were entered and analyzed on Epi-info 7software. The statistical significance threshold used was $\mathrm{p}=0.05$. The Odds ratio was used to measure the association between the dependent variable and the other explanatory variables. For the low theoretical numbers, the Yates or Fischer correction is used according to the theoretical values. The results are affected by a $95 \%$ confidence interval. The study obtained the agreement of the chiefs of the districts and each chief Fokontany where we carried out our investigation. The free and informed consent of the respondents was respected before each inclusion. This study respected the notion of volunteering, anonymity and confidentiality.

\section{RESULTS AND ANALYSIS}

\subsection{Care Received by Infants}

In total, the study involved 420 mother-child pairs. Table 1 shows the proportion of quality care received by infants. Concerning the nutrition care, only 47.6\%, 95\% CI [42.8-2.4] of infants receive acceptable care. Of these infants, just over half $(55.20 \%)$ of infants under 6 months of age are exclusively breastfed, $74.28 \%$ benefited from breastfeeding until 24 months of age, $91.80 \%$ of infants older than 6 months had dietary diversity, $40.95 \%$ had a diet adequate amount, and $17.14 \%$ have good food hygiene. Infants aged 3 to 6 months are the least monitored for food and severe malnutrition only affects these infants.

Table 1. Proportion of Types of Care Received by Infants

\begin{tabular}{lcrc}
\hline \multicolumn{1}{c}{ Types of care } & \multicolumn{2}{c}{ Quality of care } & \multirow{2}{*}{ 95\% CI } \\
& $\mathrm{n}$ & $\%$ & \\
\hline Nutrition care & 200 & 47.6 & $42.8-52.4$ \\
Social care & 388 & 92.3 & $89.8-94.8$ \\
Body hygiene care & 148 & 35.2 & $30.6-39.8$ \\
Life hygiene & 279 & 66.4 & $61.6-70.6$ \\
Health care & 191 & 45.5 & $40.9-50.5$ \\
Complete care for the five types & 32 & 7.6 & $5.1-10.1$ \\
\hline
\end{tabular}

With respect to social care, $92.3 \%, 95 \%$ CI [89.8-94.8], infants have a copy of birth certificate, of which only $14.3 \%$ are infants under 28 days of age. Of these infants, $76.2 \%$ are accepted by the biological father.Concerning the body hygiene care, the older the infant, the more adequate body hygiene care is provided (daily bathing, regular baths, clean and ironed clothes, clean diapers or nappies, regular nail clipping). Only 35.3\%, 95\% CI [30.6-39.8] of these infants received acceptable care. Among these infants: 
$20 \%$ have daily bathing, $40.9 \%$ regular baths, $40 \%$ have clean and ironed clothes, $83.8 \%$ are regularly changed with clean nappies or diapers, and $15.2 \%$ enjoy regular nail cut.

Similarly, the more the child grows, the more he takes care of the hygiene of the life (appropriate sleep hours, use of mosquito nets, toys adapted to their age, partners of game, walk, accessories adapted to each season as hat, socks and blanket). According to the hygiene of life, 66.4\%, 95\% CI [61.6-70.6] of infants receive adequate care. Of these infants, $47.1 \%$ have adequate sleep hours, $74.8 \%$ sleep under a mosquito net, $44.8 \%$ play with age-appropriate toys and $73.8 \%$ have play partners, $77,14 \%$ are taken for walks, and $43.8 \%$ have accessories adapted to each season (hat, socks, blanket).

Furthermore, health care concerns routine visitation, deworming, medical consultation and vaccination. According to health care, 45.5\%, 95\% CI [40.9-50.5] of infants received adequate care. For vaccination, $89.1 \%$ are correctly vaccinated. Deworming affects $64 \%$ of infants older than 12 months, but only $47.7 \%$ have received vitamin A. As the age of the infant increases, they are less likely to benefit routine visits, with only $25.4 \%$ of infants less than 12 months. Regarding the medical consultation, $66.7 \%$ of the infants in the survey who had already fallen ill were able to benefit from it.

\subsection{Factors Associated with Complete Care}

Otherwise, Table 2 shows that the mother's socio-economic characteristics have a positive or negative influence on the care of infants.

Table 2. Association between the Mother's Socio-Economic Characteristics and the Care Received by the Infant $(\mathrm{N}=420)$

\begin{tabular}{|c|c|c|c|c|c|c|}
\hline \multirow{2}{*}{$\begin{array}{c}\text { Mother's socio- } \\
\text { economic characteristics }\end{array}$} & \multicolumn{2}{|c|}{ Complete care } & \multicolumn{2}{|c|}{ Incomplete care } & \multirow{2}{*}{ OR } & \multirow{2}{*}{$95 \% \mathrm{CI}$} \\
\hline & $\mathrm{n}=32$ & $\%$ & $\mathrm{n}=388$ & $\%$ & & \\
\hline \multicolumn{7}{|l|}{ Age range(years) } \\
\hline 17 and less & 6 & 18.8 & 26 & 81.3 & 3.25 & $1.07-9.46$ \\
\hline 18 à 34 & 22 & 6.6 & 310 & 93.4 & 1 & \\
\hline 35 and more & 4 & 7.1 & 52 & 92.9 & 1.08 & $0.30-3.51$ \\
\hline \multicolumn{7}{|l|}{ Study level } \\
\hline Illiterate & 0 & 0.0 & 42 & 100.0 & NA* & \\
\hline Primary & 5 & 8.3 & 67 & 91.7 & 0.75 & $0.24-2.19$ \\
\hline Secondary & 22 & 9.1 & 220 & 90.9 & 1 & \\
\hline University & 5 & 6.3 & 59 & 93.8 & 0.85 & $0.27-2.50$ \\
\hline \multicolumn{7}{|l|}{ Training course } \\
\hline No & 17 & 7.7 & 191 & 92.3 & 1.29 & $0.59-2.80$ \\
\hline Yes & 15 & 6.9 & 217 & 93.1 & & \\
\hline \multicolumn{7}{|l|}{ Profession } \\
\hline Housewife & 19 & 8.7 & 189 & 91.3 & 1.54 & $0.70-3.41$ \\
\hline Working woman & 13 & 6.6 & 199 & 93.4 & & \\
\hline \multicolumn{7}{|l|}{ Marital status } \\
\hline Single & 7 & 19.4 & 29 & 80.6 & 3.47 & $1.24-9.35$ \\
\hline Married & 25 & 6.5 & 359 & 93.5 & & \\
\hline \multicolumn{7}{|l|}{$\begin{array}{l}\text { Number of dependent } \\
\text { children }\end{array}$} \\
\hline$\leq 4$ & 32 & 14.9 & 266 & 85.1 & NA & \\
\hline$>4$ & 0 & 0.0 & 22 & 100.0 & & \\
\hline \multicolumn{7}{|l|}{ Family planning } \\
\hline No & 21 & 9.3 & 195 & 90.7 & 1.89 & $0.84-4.31$ \\
\hline Yes & 11 & 5.9 & 193 & 94.1 & & \\
\hline \multicolumn{7}{|l|}{ Daily income } \\
\hline$\leq 2$ dollars & 20 & 8.8 & 206 & 91.2 & 1.47 & $0.66-3.30$ \\
\hline$>2$ dollars & 12 & 6.2 & 182 & 93.8 & & \\
\hline \multicolumn{7}{|l|}{ Access to water } \\
\hline Home & 10 & 8.8 & 104 & 91.2 & 1.24 & $0.53-2.50$ \\
\hline Fountain & 22 & 7.2 & 284 & 92.8 & & \\
\hline
\end{tabular}

\section{DISCUSSIONS}

\subsection{Profile and Proportion of Care}

Concerning the nutrition care, this study found that infants receive adequate feeding care in almost half of all cases. Just over half of infants under 6 months of age have exclusive breastfeeding. This is high compared to the 2012 United Nations of International Children's Emergency Fund (UNICEF) survey, which showed that exclusive breastfeeding affects only $20 \%$ of all infants under 6 months in Central and West Africa [10]. Regarding social care, $92.39 \%$ of infants have a copy, which is similar to Demographic health survey DHS IV, which states that $80 \%$ of children under 5 years of age are registered [11]. 
In addition, healthy lifestyle and body hygiene care increases with the age of the child Indeed, the more the baby grows, the more the mother gives him attention, which could explain this situation.Regarding health care, less than half of infants are concerned. Indeed, the routine visit concerns only one third of infants. And even, this rate decreases as the infant increases in age. According to all the mothers, they do not know that the infant needs routine visits after the last vaccine. Similarly, mothers often underestimate deworming, yet the World Health Organization (WHO) says that increased coverage of deworming significantly decreases the proportion of helminthiases in children [12].

Nevertheless, mothers do not underestimate medical consultations. Indeed, sick children are taken to medical consultation in more than half of the cases. Other mothers who do not take children to medical consultation have practice either self-medication or traditional medicine. The older the infants, the more they are no longer brought to a medical consultation. The economic problem is one of the common obstacles preventing mothers from taking their children to medical consultation.

Regarding vaccination, there has also been a marked improvement. In fact, $89.04 \%$ of infants are correctly vaccinated. On the other hand, DSH IV shows that $55 \%$ of infants are correctly vaccinated according to the EPI schedule [11]. Exactly, efforts have been made by the government and UNICEF to improve the vaccination coverage rate (purchase of vaccines, reinforcement of the cold chain, transport of vaccines, identification of areas of low coverage). Unfortunately, the unvaccinated $10.9 \%$ still pose a risk of disease development.

\subsection{Association between the Mother's Socio-Economic Characteristics and the Care Received by the Infant}

Regarding the relationship between the age of the mother and the care received by the infant, mothers over the age of 35 are the least likely to provide acceptable care for their children. Indeed, mothers are elderly and do not have enough time, physical strength, or think they have enough experience in the care of the infant. Similarly, the majority of them do not do some training about infant care. Younger mothers (under age 18) are the best to care their children. These young mothers feel less competent and follow the advice of health professionals. Other studies have also shown the contribution of young mothers in caring for her children $[13,14]$.

For the relationship between the mother's level of education and the care received by the infant, none of the illiterate mothers provide adequate care for their children. In fact, these illiterate mothers do not understand. The informations given by health workers. Similarly, they do not take their children to health center [15]. With regard to the relationship between the training course received by the mother and the care the infant receives, mothers who have not received training are more likely to provide acceptable care to their children. Indeed, the mothers, having received training, do not change their habits. On the other hand, mothers who have not received any training get more information from their entourage (grandmother, aunt). According to marital status, single mothers are more likely to provide acceptable care to their children. This situation could be due to the fact that these mothers are helped by other members of the family.

The number of housewives providing adequate care for their infants is slightly higher than that of working mothers. In fact, stay-at-home mothers have much more time to spend with their infants, unlike working mothers who often spend their time working to improve the family's income. Similarly, the literature shows that mothers' maternity leave has a positive influence on the health of infants [16]. For mothers with a daily income of more than \$ USD 2, they care less for their infants. Indeed, it is the nannies who take care of their children.

According to the results, all mothers with more than 4 dependent children do not provide quality care to their infants. Indeed, these mothers are either too busy with several children to raise, or they let the elders of her children take care of other siblings. This care is not totally adequate. Nevertheless, according to the literature, siblings are still necessary because siblings play an important role in the psychomotor development of infants [17].

For family planning, practicing mothers are usually elderly women who want to limit the number of children. Thus, their children do not receive adequate care. Regarding the relationship between access to water and the care received by the infant, mothers with access to water at home have more acceptable care. Of course, the quality of personal hygiene, food hygiene and lifestyle depend of the access to water. According to the results of this study, all the elements constituting the profile of the mother have a great impact on the care received by the infant.

At the end of this study, suggestions are proposed for the improvement of this care provided to infants. They focus on strengthening the communication strategy on infant first aid gestures and educating mothers on childcare. Enforcement of the rights of women with infants under 24 months of age and the delivery of birth copies are also required. Finally, health centers also need to improve service provision for the care of infants. Finally, we suggest extending this type of study nationally for Madagascar. 


\section{CONCLUSION}

This study has shown that the mother's socio-economic and demographic profile has a considerable influence on the different care received by the infant. Our results have their limits from the point of view of representativeness. However, they inform us about the mother's behavior regarding the care she offers to her child according to her socio-economic profile. Thus, the government and the Ministry of Health should design a new targeted program to promote mother's training and raise the standard of living of the population in order to achieve the current goal: "Health for mother and child".

\section{REFERENCES}

[1] Preamble to the Constitution of the World Health Organization, as adopted by the International Conference on Health, New York, 19 June-22 July 1946; signed on 22 July 1946 by the representatives of 61 States. (Official Records of the World Health Organization, No. 2, p.100) and entered into force on April 7, 1948.

[2] World Health Organization. World Health Report. Primary Health Care-Now more than ever. WHO, Geneva, ISBN 9789242563733 ISSN 1020-332X, 2008.

[3] Report of the Economic, Social and Environmental Council in Morocco. Basic health care: Towards equitable and widespread access. Reference 4/2013: 111p. ISBN:978-9954-9389-3-5 ISSN : 2335-9242, Available from: www.cese.ma, 2018.

[4] World Health Organization. Global health statistics 2014. WHO, Geneva, 2014: 178p. ISBN 9789240692688 , 2014.

[5] United Nations of International Children's Emergency Fund. 70 years for each child. The situation of children in the world in 2016: equal opportunities for every child. UNICEF, New York, ISBN: 978-92-806-4839-3. [cited 2018 Feb 6]. Available from : www.unicef.data.org, 2016.

[6] United Nations of International Children's Emergency Fund. Abstract of the Investment Plan for Nutrition in Madagascar. UNICEF, 15 p, 2017.

[7] National Monitoring Survey of the Millennium Development Goals in Madagascar, 2012-2013.

[8] Global prevalence of vitamin a deficiency in populations at risk 1995-2005. WHO Global Database on Vitamin a Deficiency, 2009

[9] UNICEF, WHO, UNESCO, UNFPA, UNDP, UNAIDS, WFP, WORLD BANK. Facts for life. 4th edition. UNICEF, New York Apr 2010: 194p. ISBN: 978-92-806-4466-1

[10] Sokol E, Aguayo VM, Clark D., "Protect breastfeeding in West and Central Africa. 25 years of application of the International Code on the Marketing of Breastmilk Substitutes" Dakar : Unicef - Regional Office for West and Central Africa; 2007. 44 p. [cited 2018 Jan 8]. Available from: http://www.unicef.org/wcaro/WCAR_Proteger_allaitement_maternel_Code_commercialisation_Fr.pdf.

[11] Institut National de la Statistique (INSTAT) and ICF Macro, "Demographic and Health Survey of Madagascar 2008-2009”, Antananarivo, Madagascar: INSTAT and ICF Macro, 2010.

[12] World Health Organization, "Continuing Action To Reduce The Global Impact Of Neglected Tropical Diseases: Second WHO Report On Neglected Tropical Disease”, WHO, Geneva: 138p ISBN 978924256454 9, 2014.

[13] Luster, T., \& Brophy-Herb, H., "Adolescent Mothers and Their Children. In D.Osofsky \& H. E. Fitzgerald (Eds.)" WAIMH Handbook ofinfant mental health, Vol": Infant mental health in groups at high risk. New York: Wiley, 2000.

[14] Jahromi, L. B., Putnam, S. P., \& Stifter, C. A., "Maternal Regulation of Infant Reactivity from 2 to 6 Months," Developmental Psychology, 40:477-487, 2004.

[15] Adam Wagstaff, "Poverty and inequalities in the health sector," Bulletin of the World Health Organization, 80(2): 97-105, 2002.

[16] Fiossi Kpadonou É, Odjo A, Djidonou A, Kpadonou TG., "Baby's intentional smile and maternal associated factors," Neuropsychiatrie de l'Enfance et de l'Adolescence, 65(5):281-8, 2017.

[17] Nina Howe, Holly Recchia., "Fraternal relations and their impact on children's development," Peer relations, CEDJE/RSC-DJE. Ed rev Jan 2015: 1-9. [cited 2018 Jun 6]. Available from: http://www.enfantencyclopedie.com/sites/default/files/textes-experts/fr/101/les-relations-fraternelles-et-leur-impact-sur-ledeveloppement-des-enfants.pdf, 2015. 